Boise State University

ScholarWorks

Public Policy and Administration Faculty

Publications and Presentations

Department of Public Policy and Administration

$7-2020$

\title{
Best Practices for Implementing Federal Environmental Policies: A Principal-Agent Perspective
}

Luke Fowler

Boise State University

Publication Information

Fowler, Luke. (2020). "Best Practices for Implementing Federal Environmental Policies: A Principal-Agent

Perspective". Journal of Environmental Planning and Management, 63(8), 1453-1469. https://doi.org/

10.1080/09640568.2019.1670627

This is an Accepted Manuscript of an Article published in Journal of Environmental Planning and Management on July 2020, available online at https://doi.org/10.1080/09640568.2019.1670627 


\title{
Best Practices for Implementing Federal Environmental Policies: A Principal-Agent Perspective
}

\author{
Luke Fowler \\ Boise State University
}

\begin{abstract}
In the U.S., federal environmental policies tend to be implemented by subnational agencies through intergovernmental management systems, which results in state governments serving as agents of the Environmental Protection Agency (EPA). Therefore, principal-agent dynamics create a key challenge for implementing federal environmental policies, as goal incongruence and information asymmetries lead to conflict. As such, we argue some best practices are those that mitigate principal-agent problems by reducing information asymmetries or aligning actions with expectations of both principals and agents. Drawing data from the EPA's evaluations of state programs, the authors identify and examine 68 best practices. Findings suggest that viewing implementation of federal environmental policies as an exercise in managing principal-agent dynamics can help reduce conflicts between organizations working together to address complex environmental problems.
\end{abstract}

Keywords: intergovernmental, policy implementation, principal-agent, best practices

\section{Introduction}

In the United States (U.S.), implementation of the Clean Air Act (CAA), Clean Water Act (CWA), and Resource Conservation and Recovery Act (RCRA) occurs through an intergovernmental management system. Under this system, the U.S. Environmental Protection Agency (EPA) is responsible for establishing and implementing national standards for environmental quality. However, EPA can delegate primary enforcement and implementation authority (referred to as primacy) to state agencies, under the assumption that decentralization will result in programs that are more responsive to local needs. Previous research on the effectiveness of this approach is mixed with some arguing it results in a "race-to-the-top" and others arguing that it provides states with a bargaining tool to use against EPA (Potoski, 2001; Woods 2006a, 2006b; Koski, 2007; Konisky, 2007). Most scholars agree that states have different levels of capacity for and political commitment to environmental protection, which serves as a major factor in determining program effectiveness (Lester, 1995). Additionally, when EPA and state agencies enjoy cooperative relationships, programs tend to be more successful, but when conflict emerges, programs suffer (Peterson, 1995; Scheberle, 2004, 2005; Woods, 2006a, 2006b; White and Boswell, 2006). Consequently, there is likely a set of best practices that can maximize capacities and improve cooperation.

Despite the preponderance of public service delivery networks in recent decades though, the primacy system still largely relies on hierarchical organization and principal-agent relationships. From this perspective, EPA serves as a principal overseeing state agencies, where it controls resources, structures regulatory processes, and defines successful implementation (for the most part). On the other hand, state and local agencies implement policies and pioneer new innovative management practices to address environmental problems (Woods, 2006b; Ma, Beckers, and Kilgore, 2009, 2012; Terman and Feiock, 2015; Paul and Milman, 2017). This highlights a key principal-agent challenge for policy implementation, where agents develop management practices to serve their interests but principals play a significant role in defining the value of those practices. As such, principals' subjective interpretations of management practices serve as a key measurement of "best." Consequently, in implementing federal environmental policies, best practices may be those that mitigate principal-agent problems in order to satisfy EPA. For state agencies, this likely means being a "good" agent above all else.

As such, this paper investigates: what practices does EPA perceive as best for implementing the CAA, CWA, and RCRA? In addressing this question, we first discuss best practices, principal-agent dynamics in policy implementation, and implementation styles. Then, drawing data from EPA evaluations of state implementation programs, we identify 68 best practices across 23 states and the District of Columbia. Findings indicate that best practices tend to reduce 
This is an author-produced, peer-reviewed version of this article. The final, definitive version of this document can be found online at Journal of Environmental Planning \& Management, published by Taylor \& Francis. Copyright restrictions may apply. https://doi.org/10.1080/09640568.2019.1670627

information asymmetries and align actions with expectations of both principals and agents. These include practices such as reporting more data than required, under-promising and over-delivering, focusing on corrective enforcement actions, and linking monitoring efforts with enforcement, compliance, and reporting. But, which practices are best varies based on trust in state agencies and regulated facilities. Conclusions suggest that viewing policy implementation as an exercise in managing principal-agent relationships can help reduce inter-organizational conflicts when implementing federal environmental policies.

\section{Best Practices}

Best practices are a well-established concept in management of public programs, as "academics and practitioners have long recognized high-performing public sector organizations and sought ways to close the performance gap between the least and most effective organizations" (Hall and Jennings, 2008, p. 695). This places value on connecting theory to practice in order to improve actual performance by practitioners, which is common in most applied fields (e.g., medicine, management). As a result, both practitioners and scholars find significance in activities that successfully link actions and goals in a process comparable between organizations (Bretschneider, Marc-Aurele, and Wu, 2005; Hall and Jennings, 2008; Centner and Eberhart, 2016). Although there is some debate over the specific meaning, Bretschnedier, Marc-Aurele, and Wu (2005) offers a fairly succinct description: best practices "implies that it is best when compared to any alternative course of action and that it is a practice designed to achieve some deliberative end" (p. 309).

Hall and Jennings (2008) adds some nuance to this meaning by differentiating between two types: 1) promising practices in which practitioners pioneer activities that successfully improve societal problems in specific instances; and, 2) evidence-based practices in which scholars apply rigorous methodologies to provide evidence that a practice has generalizable positive effects on societal problems. As Hall and Jennings (2008) indicates, a key issue with best practices support for the claim that these practices are indeed "best." While best practices research suffers from numerous methodological challenges that limit generalizability, a core challenge is that "best" tends to be a subjective term with alternative definitions from different stakeholders (Bretschneider, Marc-Aurele, and Wu, 2005; Myers, Smith, and Martin, 2006; Jennings and Hall, 2012). As such, practices developed by some agencies may not fit the definition of "best" used by other agencies. This is particularly interesting in the context of environmental policy implementation, where different environmental agencies may have different perspectives on what "best" means in terms of processes and outcomes (Ma, Becker, and Kilgore, 2009, 2012; Paul and Milman, 2017).

\section{Principals, Agents, and Policy Implementation}

In its simplest form, agency theory describes the relationship between two rational utility maximizers entering into a service agreement. Problems arise when one party has more, better, or different information than the other party (i.e., information asymmetry) and uses this to their advantage. For instance, bureaucrats may take advantage of a lack of legislative knowledge on application of policy to real-world scenarios in order to pursue self-interested goals that may conflict with legislative goals. Although classic political science examples revolve around legislative-bureaucratic dynamics, other scholars use agency theory to describe interactions between two (or more) bureaucratic agencies as well as between bureaucratic agencies and other actors (e.g., regulated industries) encountered during policy implementation (Waterman and Meier, 1998; Miller, 2005; Terman and Feiock, 2015). This is particularly important given the system by which federal environmental policies are implemented in the U.S., as EPA relies significantly on states as agents to implement the CAA, CWA, and RCRA.

The basis of this relationship is the delegation of primacy to state agencies with EPA retaining oversight authority to determine if states are effectively complying with national standards and guidelines (Woods, 2006b). Currently, 50 states have primacy for CAA programs, 46 states for CWA programs, and 48 states for RCRA programs (EPA, 2018). Furthermore, similar principal-agent dynamics occur where state environmental agencies serve as principals to facilities regulated under these environmental programs. Here, regulated facilities serve as de facto agents of state environmental agencies by conforming business practices to regulations and guidelines established through the implementation process (Miller, 2005). For example, environmental regulatory agencies tend to require industrial facilities to abide by a set of management practices that minimize pollution in order to comply with environmental quality standards. Given these trends, environmental policy implementation largely occurs within a layered system of principal-agent relationships. Although they may take on different dynamics, agency theory generally describes these relationships (Waterman and Meier, 1998; Peters, 2014; Ruffing, 2015; Terman and Feiock, 2015). 
This is an author-produced, peer-reviewed version of this article. The final, definitive version of this document can be found online at Journal of Environmental Planning \& Management, published by Taylor \& Francis. Copyright restrictions may apply. https://doi.org/10.1080/09640568.2019.1670627

To this end, when information sharing and goal consensus occur, trust forms, relationships become reciprocal, agents enjoy more discretion, and principals are less burdened. As such, policy implementation becomes a less challenging process as transaction costs are minimized and relationships become more cooperative and less conflictual (Waterman and Meier, 1998; Miller, 2005; Carpenter and Krause, 2015). In theory, reaching an equilibrium of information sharing and goal consensus between principal and agent should alleviate the core principal-agent problems. In practice though, it is impractical to assume that institutional mechanisms can effectively overcome self-interested behavior by agents (Hindmoor, 1998; Miller and Whitford, 2002; Whitford, 2002; Miller, 2005). However, we can assume that a set of best practices can create confidence for principals that their agents are both sharing information and acting consistently with their goals (Poth and Selck, 2009; Carpenter and Krause, 2015). In other words, for a state agency implementing federal environmental policies, best practices reduce distrust with both EPA above and regulated facilities below, even if they do not remove self-interested behavior from the equation (Hindmoor, 1998; Miller and Whitford, 2002).

Within this context, best practices then are practices that make for "good" principals and/or "good" agents; that is, practices that mitigate the inherent conflicts in a principal-agent relationship by reducing the burden of principals in oversight and ensuring agents act as expected. However, given dual roles of state agencies, they face managing information asymmetries and goal conflicts as both principals and agents (Hedge, Scicchitano, and Metz, 1991; Terman and Feiock, 2015). Within this framework, the goal as an agent is to create reasonable confidence in their principal that information is shared and work is not shirked in order to obviate the need for EPA to seize more control over the implementation process. On the other hand, the goal as a principal is to be reasonably confident in the available information on regulated facilities and that their behaviors align with your goals, so there is no need to develop further control. In practice, if this equilibrium is achieved, then principal-agent problems can be effectively mitigated and policy implementation will likely occur within a scenario similar to a classic policy subsystem. In other words, principals and agents can reach a relative detente and ease the need for "game playing" (Waterman and Meier, 1998; Miller, 2005; Lane, 2006).

Based on this, best practices in policy implementation can be divided into four categories: reporting, compliance, monitoring, and enforcement (see figure 1). First, with state agencies in the role of agent, best reporting practices from state agencies involve sharing information with principals, such as providing regular reports on inspection or enforcement actions. Second, with state agencies in the role of principal, best monitoring practices involve gaining information on regulated facilities; for example, by performing routine inspections. In both cases, these practices reduce information asymmetries (actual or perceived) so principals understand what their agents are doing and if they are performing as expected (Wholey and Hatry, 1992; Waterman and Meier, 1998; Miller, 2005). Third, with state agencies in the role of agent, best compliance practices involve taking steps to fulfill obligations to EPA, such as hiring a compliance coordinator to track progress towards goals. Fourth, with state agencies in the role of principal, best enforcement practices involve encouraging regulated facilities to fulfill their obligations, such as using inducements for pro-environmental behavior. In both cases, the purpose of these practices is alignment of agents' efforts with principals' expectations, so principals can be confident that agents are not taking advantage or supplanting the principal's goals in favor of their own (May and Wood, 2003; May, 2005; Miller, 2005).

\section{[Figure 1 about here]}

As policy implementers use a variety of management practices, best practices from a principal-agent perspective satisfy both of these goals, as implementing agents act as both "good" agents and "good" principals. However, these best practices may manifest differently based on administrative or implementation styles (Matland, 1995; Howlett, 2004). As Howlett (2005) phrases it: "Why is a particular combination of procedural and substantive instruments utilized in a specific sector?" (pg. 46). In this context, procedural refers to practices designed to alter implementation processes, while substantive, to those designed to alter the underlying goals or logic of implementation. Although there are numerous dimensions by which implementation styles can be identified, two common threads are: 1) trust in state-societal relations and/or the legitimacy of systems; and, 2) the national versus sectoral-level (Howlett, 2004). As this applies, to the federal environmental policy, we can infer that best practices likely differentiate based on the level of trust (or perceptions of legitimacy) that EPA has in state agencies to implement policies (i.e., national system) and in regulated facilities to comply with those policies (i.e., sectoral-level). Consequently, we can further break-down our four categories of best practices based on these two dimensions (see Figure 2).

\section{[Figure 2 about here]}


This is an author-produced, peer-reviewed version of this article. The final, definitive version of this document can be found online at Journal of Environmental Planning \& Management, published by Taylor \& Francis. Copyright restrictions may apply. https://doi.org/10.1080/09640568.2019.1670627

First, reporting practices largely assume a low degree of trust in state agencies, as EPA seeks to reduce information asymmetries. Best practices, then, differ depending on whether EPA trusts facilities at the sectoral-level to comply with policies, which alters which actor in the system they seek to obtain more information from (i.e., is the information asymmetry with regulated facilities or state agencies?). Second, compliance practices largely assume a high degree of trust in state agencies and that state implementation processes align with EPA goals. Here, best practices differ based on EPA trust at the sectoral-level, which alters how they believe state agencies should interact with regulated facilities (i.e., can we assume that regulated facilities will comply?). Third, enforcement practices assume EPA has a low degree of trust in regulated facilities, so they must be induced into compliance. But, best practices depend on whether EPA trusts state agencies to enforce regulations in a way that aligns with national goals, which shifts practices from procedural- to substantive-based (i.e., can state agencies be trusted to design inducements on their own?). Fourth, monitoring practices assume a high degree of trust in regulated facilities and that monitoring alone is enough to induce compliance. Nevertheless, if there is a low degree of trust in state agencies, best practices are likely to be more procedural than substantive in order to ensure monitoring is effective (i.e., can state agencies effectively monitor regulated facilities?) (Waterman and Meier, 1998; Whitford, 2002; Miller, 2005).

\section{Identifying Best Practices in Policy Implementation}

We draw data from EPA's State Review Framework for Compliance and Enforcement Performance (SRF) program, which evaluates state programs for implementing the CAA, CWA, and RCRA. Although EPA has routinely evaluated state programs since the inception of primacy, growing criticisms of inconsistent and inequitable evaluations in the early 2000s led to a collaboration between EPA, the Environmental Council of the States (ECOS), and state agencies to develop a uniform assessment tool. As a result, the SRF program was launched in 2004 "to evaluate state performance to (a) provide a consistent level of environmental and public health protection across states; and (b) develop a consistent mechanism by which EPA Regions, working collaboratively with their states, can ensure that authorized state agencies meet agreed-upon performance levels" (EPA, 2005, p. 1). Following a first round of evaluations between 2004 and 2007, EPA revised the SRF evaluation instrument, and a second round occurred between 2009 and 2013. Although a third round began in 2015, complete results are currently unavailable. EPA and ECOS designed SRF evaluations to be collaborative in nature with EPA and state agencies developing a mutual understanding of issues, causes, and needed courses of corrective actions.

In conducting evaluations, EPA personnel review data from the national data system and a sample of state files related to data, inspections, violations, enforcements, and penalties, which are subdivided into twelve program elements. Generally, evaluations rely on quantitative data metrics, but when applicable, evaluators also provide qualitative comments and recommendations for improvement (online Appendix $\mathrm{C}$ provides definitions for program elements used for evaluations). SRF evaluations provide an adept tool for understanding best policy implementation practices, as they both collect objective data on state programs and provide a subjective analysis of the quality of specific actions within those programs. As state agencies serve as an intermediary between EPA and regulated facilities, two types of principal-agent relationships exist: one where state agencies serve as the agents of EPA; and, one where state agencies serve as the principals of regulated facilities. Since state agency roles as principal and agent are intertwined, EPA has a vested interested in states being both an effective principal and agent. SRF evaluations are then an evaluation of both relationships from the perspective of EPA. As such, this provides us with two important pieces of data: 1) what practices state agencies use in environmental policy implementation; and, 2) how EPA personnel perceives these practices.

Although SRF evaluations primarily rely on a three-category scale (meets expectations; needs attention; needs improvement) for rating program elements, a "good practices" distinction is awarded in some cases. By definition these are: "activities, processes, or policies that the SRF data metrics and/or the file reviews show are being implemented exceptionally well...Additionally, the report may single out specific innovative or noteworthy activities, process, or policies that have the potential to be replicated by other States and that can be highlighted as a practice for other states to emulate" (EPA, 2010, p. 3). Although labeled "good practices," this definition largely conforms to definitions of "best practices" or "promising practices" used in previous research; although they would not be considered "evidence-based practices" (Bretschneider, Marc-Aurele, and Wu, 2005; Hall and Jennings, 2008; Jennings and Hall, 2012). Importantly, these represent perceptions of EPA evaluators, and are not a systematic analysis of which practices are most effective in managing environmental programs. Consequently, these perceptions are biased, but that bias aligns with our presumption that principals are likely to perceive certain practices as better than others based on their interests. 
This is an author-produced, peer-reviewed version of this article. The final, definitive version of this document can be found online at Journal of Environmental Planning \& Management, published by Taylor \& Francis. Copyright restrictions may apply. https://doi.org/10.1080/09640568.2019.1670627

To analyze this data, we reviewed SRF reports from the second round of evaluations and identified 68 good practices across 11 program elements. These included 28 from CAA programs, 15 from CWA programs, and 25 from RCRA programs, across 23 states and the District of Columbia. SRF reports provided brief descriptions of practices, including an explanation of why it qualified as a good practice. While this provides the data to substantiate this analysis, we then had to apply qualitative analysis techniques in order to ascertain more specific dimensions represented within these data. As such, we developed a decision tree for coding good practices into four categories (reporting, monitoring, compliance, and enforcement) (see online Appendix A). First, we separated practices by whether the primary focus is managing information or actions. If the former, we deduced that the practice is relative to reducing information asymmetries; if the latter, relative to aligning actions with expectations.

Then, we further refined these categories. For practices related to information asymmetries, we separated practices based on whether the primary focus is on obtaining or sharing information. If sharing information, we determined it to be a reporting practice; if obtaining information, a monitoring practice. For practices related to aligning actions with expectations, we separated practices based on whether the primary focus is on actions internal or external to the implementing organization. If internal, we determined it to be a compliance practices; if external, an enforcement practice. Based on these steps, we identified 24 practices related to reporting, 16 related to monitoring, 17 related to compliance, and 11 related to enforcement (online Appendix B provides a breakdown by function and state program). Finally, within each functional category, we further grouped categories based on general trends and themes, using a quasi-grounded theory approach (i.e., we identified patterns and repeated ideas) (Creswell and Poth, 2018). In some cases, descriptions of practices included multiple aspects, which connected to different themes. Below, we described these themes with specific examples noted to illustrate best practices for policy implementation.

\section{Best Practices}

Table 1 provides a summary of these themes by function, as well as specific examples from SRF reports. Additionally, figure 3 categorizes best practices based on implementation style. In general, there are certain best practices in each category that align with our predicted break-down and reflect differential degrees of trust in state agencies and/or regulated facilities as it relates to information and/or compliance with national policy guidance.

\section{[Table 1 and Figure 3 about here]}

\section{Reporting}

Reporting best practices tend to focus on procedural elements to improve information management. Although EPA has minimum data reporting requirements for state agencies, data completeness, accuracy, and timeliness of entry are frequently identified deficiencies. In many cases, EPA has difficulty determining whether both state agencies and facilities are complying with national environmental regulations, creating a significant information asymmetry. High quality reporting practices increase trust between EPA and state agencies, but differ based on trust at the sectorallevel. For instance, there are at least 20 best practices that can be described as meticulous recording of information and/or recording more information than is required. Examples of this includes Rhode Island's Department of Environmental Management (RIDEM) tracking of both formal and informal enforcement actions, and inspectors from Arizona's Department of Environmental Quality (AZDEQ) incorporating photographic evidence into reports to document conditions at the time of inspection. These type of reporting practices assume that neither state agencies nor regulated facilities should be highly trusted, so EPA wants to "look over the shoulder" of state agencies during the process of inspecting, monitoring, and enforcing regulations.

On the other hand, there are four best practices that relate to data quality control checkpoints that help ensure data is both complete and accurate. For instance, at Massachusetts's Department of Environmental Protection (MADEP), there is a central point of contact responsible for data quality control that performs monthly checks, and staff from Virginia's Department of Environmental Quality (VADEQ) work with EPA's Regional State Liaison Officer to review data before entering it into national databases. In contrast to meticulous data collection, best practices in this area would suggest the issue lies with how information flows through state agencies to EPA, rather than how information flows from regulated facilities to state agencies. That is, EPA is less concerned that a large quantity of information is collected, and more concerned that collected data is accurately reported. While both types of best practices provide EPA with a better understanding of conditions at regulated facilities and state implementation actions, the difference stems from where EPA perceives potential information asymmetries to occur based on trust at the sectoral-level. 
This is an author-produced, peer-reviewed version of this article. The final, definitive version of this document can be found online at Journal of Environmental Planning \& Management, published by Taylor \& Francis. Copyright restrictions may apply. https://doi.org/10.1080/09640568.2019.1670627

\section{Compliance}

While failure to comply with national guidelines or meet minimum expectations for performance metrics (e.g., number of facility inspections) seems to be a significant area of shortcomings for state programs, SRF reports identify few best practices in this area. High quality compliance practices assume a certain level of trust between EPA and state agencies, but differ based on trust at the sectoral-level. In many cases, a rating of "good practices" tend to be based on states meeting or exceeding the minimum commitments, and not specifically on having developed an innovative way of meeting goals. Although reports provide few concrete answers, best practices appear to be those that create an impression that work shirking has not occurred (i.e., not falling short of expectations). For example, AZDEQ's CAA program committed to inspecting 33 facilities but actually inspected 38, and RIDEM's RCRA program committed to inspecting 91 facilities but actually inspected 125. Interestingly, Maine's Department of Environmental Protection (MEDEP) and Nevada's Division of Environmental Protection (NVDEP) were also identified as using best practices as they met set inspection goals while facing staffing shortages that should have otherwise limited capacity.

From these examples, we can infer that these agencies were capable of performing more inspections than originally committed to, with AZDEQ and RIDEM exceeding goals under normal capacity and MEDEP and NVDEP meeting goals with limited capacity. As such, we can surmise that a best practice is to under-promise and over-deliver. In other words, commit to an official goal that is obtainable but aim for a higher (unofficial) goal. This strategy creates a safeguard against falling into non-compliance, and sets agencies up to over- perform. Consequently, it will be unlikely that EPA will suspect work shirking, which may be particularly important if there is a low level of trust that facilities are in compliance. On the other hand, if there is a higher level of trust at the sectoral-level, best practices focus more on effectively using resources, such as cross-training personnel so that manpower can be shifted in response to emerging challenges. For example, MADEP was able to create a more efficient inspection process by implementing cross-media inspections. As a result, one person could inspect entire facilities for a full range of issues, rather than multiple people with a limited perspective. This removes an institutional barrier in meeting inspection commitments across different program areas. As a whole, best compliance practices provide EPA with some security that state agencies faithfully comply with program goals, but may differ based on whether regulated facilities are trusted to do the same.

\section{Monitoring}

Similar to other types of highly technical regulatory policies, one of the most important and intensive activities undertaken in the implementation of environmental policies is monitoring. State agencies rely on direct monitoring, via activities like inspections, and agencies pass much of the obtained information along to EPA as part of reporting practices. Consequently, monitoring may be one of the most scrutinized areas of state programs, but also an area that produces notable best practices. High quality monitoring practices reduce information asymmetries, but differ based on trust between EPA and state agencies. When there is a low level of trust, best practices tend to focus on more procedural approaches to create uniformity in monitoring. For instance, possibly one the most basic practices consistently noted is using checklists and templates to enhance quality. EPA identifies at least eight state agencies that designed monitoring tools to ensure consistent and reliable inspections. Almost universally, EPA lauds these for improving monitoring activities. These type of monitoring practices assume that state agencies will not effectively monitoring regulated facilities without procedural requirements, although facilities may be complying with regulations.

On the other hand, when there is a high level of trust, best monitoring practices tend to focus on more substantive concerns, such as being strategic, adaptable, and tied to the local policy context. For instance, since many facilities were geographically difficult to access and some were at more risk for compliance violations than others, Wyoming's Department of Environmental Quality (WYDEQ) developed a plan that allowed them to rotate inspections of low-risk facilities on a multi-year basis but routinely inspect high-risk facilities or those where unexpected issues arose. Somewhat similarly, VADEQ designed their monitoring strategy around a risk-based protocol so leadership could focus resources on areas where violations were most likely to occur. Additionally, other best practices also note that monitoring should not be a stand-alone activity and should connect to enforcement and reporting. Although EPA found that only Louisiana's Department of Environment Quality (LADEQ) specifically links monitoring and enforcement, best practices from several states connect monitoring to successful enforcement or reporting practices. For instances, AZDEQ flags issues with potential to be future violations in routine reporting, which improves both the agency's and EPA's understanding of conditions at those facilities. Additionally, several agencies, including AZDEQ 
This is an author-produced, peer-reviewed version of this article. The final, definitive version of this document can be found online at Journal of Environmental Planning \& Management, published by Taylor \& Francis. Copyright restrictions may apply. https://doi.org/10.1080/09640568.2019.1670627

and West Virginia's Department of Environmental Protection (WVDEP), use monitoring histories to inform compliance and enforcement determinations. While both types of practices reduce information asymmetries, a key dimension is how much EPA trusts state agencies to conduct effective monitoring on its own.

\section{Enforcement}

Enforcement best practices tend to include both procedural and substantive elements to encourage violators to return to a state of compliance. From both EPA and state agency perspectives, this keeps environmental management at regulated facilities aligned with program goals. In practice, this is easier said than done, especially when enforcement may involve conflict with politically and economically important industries. Consequently, some state agencies, such as Illinois's Environmental Protection Agency (ILEPA), struggle to use enforcement tools effectively, including consistently imposing penalties and collecting fines. High quality enforcement practices assume regulated facilities are out of compliance and inducements are necessary, but differ based on EPA-state agency trust. That is, when there is a high level of trust between EPA and states, best practices focus more on substantive elements of aligning actions with expectations, but when there is a low level of trust, best practices focus on procedural elements.

To this end, there are six best practices that seem to focus more on substantive approaches to enforcement. Although several states focus on punitive tools, EPA notes that a few state agencies, such as MEDEP and RIDEM, rely first on working with violators to development a corrective action plan, and if enforcement makes it way to the courts, these agencies prefer orders of injunctive relief to monetary penalties. Additionally, corrective action plans provide a specific course of action, which ensures violators are clear on necessary steps for compliance. For instance, Texas's Commission on Environmental Quality (TXCEQ) was successful in returning 100\% of its high priority violations to compliance by just providing a detailed document of what actions were necessary and the timeframe for completing those actions. Furthermore, these plans can further encourage swift corrective action when coupled with incentives. For example, Arkansas's Department of Environmental Quality (ARDEQ) and Connecticut's Department of Energy and Environmental Protection (CTDEET) offer penalty reductions if violators agree to corrective courses of action during short windows following a finding of violations. Other state agencies, such as RIDEM and Utah's Department of Environmental Quality (UTDEQ) negotiate penalties with violators in order to find suitable solutions that achieve compliance in a timely manner. This category of best practices seems to indicate a high level of trust in the procedural capacities of states with EPA by emphasizing outcomes rather than procedural outputs.

On the other hand, there are three best practices identified related to one-size-fits-all enforcement approaches and the use of informal tools as effective in encouraging compliance. A prime example is RIDEM's use a four-tiered system, ranging from a letter of warning to formal enforcement hearings and imposition of legal penalties, with each tier becoming more aggressive and requiring additional administrative steps. In many cases, RIDEM finds violators respond positively to initial warning letters from staff so time and expenses associated with more formal actions are unnecessary. Additionally, other best practices identified focus on consistency, so all parties understand identification of and responses to violations. EPA is particularly complementary of agencies that develop data tools that outline uniform responses and provide for quick references to commonly encountered issues. For example, Oregon's Department of Environmental Quality (ORDEQ) codified their penalty assessment criteria to clearly lay out the basis of penalties and ensure consistent enforcement. In both cases, these procedurally-based enforcement practices seem to indicate a low degree of trust in state capacity by emphasizing standardization in enforcement. While both types of best practices provide EPA with more confidence that facilities are being induced into regulatory compliance, the difference stems from whether EPA trust state agencies to pursue compliance as a goal.

\section{Discussion}

Although reporting, monitoring, compliance, and enforcement are common activities in policy implementation, a principal-agent perspective provides new insights into their purposes and effectiveness. At their core, reporting and monitoring reduce information asymmetries, so best practices ensure EPA effectively understands what state agencies are doing and state agencies understand what regulated facilities are doing. These include practices such as developing data tools and mechanisms to manage information sharing and collection, communicating the situation and not just data points, being strategic in gathering data, and linking monitoring with reporting and enforcement. On the other hand, compliance and enforcement align agent actions with principal expectations, so best practices give EPA confidence that state agencies are not work shirking or pursuing their own goals, and state agencies the same confidence that regulated facilities are not violating regulations. These include under-promising and over-delivering, being consistent, focusing on corrective action, developing a range of tools to induce compliance, and preparing 
This is an author-produced, peer-reviewed version of this article. The final, definitive version of this document can be found online at Journal of Environmental Planning \& Management, published by Taylor \& Francis. Copyright restrictions may apply. https://doi.org/10.1080/09640568.2019.1670627

personnel to respond to challenges. The utility of these practices depends on how trusted state agencies and/or regulated facilities are by EPA. Although these practices may not guarantee better policy outcomes per se, they are likely to improve the principal-agent relationships in which policy implementation hinges if used within the appropriate context.

For environmental managers, these findings provide a few concrete suggestions on how to manage relationships with EPA when implementing federal policies. In general, though, these findings suggest that policy implementers should be cognizant of the inherent principal-agent dynamics of their inter-organizational relationships. In many cases, effectively managing these issues may be the difference between success and failure. Although these findings are limited to the CAA, CWA, and RCRA, many are applicable to other environmental programs, particularly those involving EPA. Additionally, these practices may be germane to other implementation arrangements involving thirdparty agencies, such as those that occur with outsourcing or contracting (Milward and Provan, 2000, 2003). As this approach has become more common in recent decades, best practices for dealing with such challenges are particularly useful as practitioners grapple with the power dynamics between multiple organization as they attempt to adapt management strategies for complex environmental problems to local needs (White and Boswell, 2006; Mees and Driessen, 2018). Nevertheless, this list is not exhaustive and there are likely other effective practices in mitigating principal-agent problems.

Importantly, there are two key caveats to these findings. First, principals may sacrifice their long-term interests for short-term gains, and principal's desires may not actually correlate with performance (Miller and Whitford, 2002; Miller, 2005). Consequently, best practices from EPA's perspective may not lead to better policy outcomes (i.e., environmental quality), which sets up a difficult balance of competing interests for state agencies. Second, some of these may reflect ways to "game the system," rather than serve as a "trusted" agent (Waterman and Meier, 1998; Miller, 2005; Lane, 2006). For example, "record more information than is required" could also be reframed as "flood EPA with information" so they become overloaded. While these two caveats suggest a more cynical perspective of managing principal-agent relationships than assumed here, ultimately, they do not change the utility of this framework in guiding environmental managers on how to effectively manage their policy implementation responsibilities. In other words, even if we make a different set of assumptions about principals and agents, our findings still suggest principal's perceptions are important in defining best practices by agents and offer strategies for managing this relationship.

However, this does suggest that our findings face both theoretical and methodological limitations. Theoretically, our framework implicitly assumes a coercive nature to intergovernmental management and that public agencies are responsible for policy implementation. While coercive federalism historically dominated environmental policy and was a key tool used by the federal government as recently as the Bush administration, contemporary scholarship indicates that federalism has trended towards a more cooperative approach in recent decades (i.e., less defined by principal-agent relationships). Under this perspective, state governments are trustees of the regulatory programs, rather than agents of the federal government (May and Burby, 1996; Agranoff and McGuire, 2001; Posner, 2007). Additionally, not all policy is implemented via this federal-state relationship or through public agencies in general (e.g., mandated markets), so these best practices are not applicable to every environmental policy. Furthermore, we also assume that goals can be specified and agents held accountable for their actions. However, research on policy implementation and organizational management suggest ambiguity is a key factor that makes goal specificity extremely difficult (Matland, 1995; Zahardias, 2014; Davis and Stazyk, 2015). Given these limitations, additional research should consider whether our findings are compatible with different perspectives on policy implementation, especially as they apply to environmental policy areas that are less rigid (e.g., climate change).

Methodologically, while data from EPA's SRF program provides some interesting insights into best practices for implementing the CAA, CWA, and RCRA, this is a limited data sample and further research is necessary. More specifically, this data sample only considers the perspectives of EPA in identifying best practices for three federal environmental programs managed by state agencies. As such, these practices may be less applicable to other environmental programs that are less asset specific or involve more complex, multi-lateral relationships (Agranoff and McGuire, 2001; Brown and Potoski, 2003). Additionally, "good practices" identified by EPA fit the definition of "promising practices" but not evidence-based research. Consequently, while there is a sense among EPA and state agency personnel that these practice are effective, there is no systematic evidence of their effects on performance (Hall 
This is an author-produced, peer-reviewed version of this article. The final, definitive version of this document can be found online at Journal of Environmental Planning \& Management, published by Taylor \& Francis. Copyright restrictions may apply. https://doi.org/10.1080/09640568.2019.1670627

and Jennings, 2008). There may also be important regional trends within this data that we have not investigated due to regional offices that may prefer different implementation styles given their relationships with state agencies, organizational cultures, or socio-political contexts.

Furthermore, as it relates to implementation styles, trust tends to be built over time, so EPA may have fundamentally different expectations for how programs operate depending on historical patterns of state implementation efforts and compliance from regulated facilities. In some cases, this may mean that relationships are "valued" outcomes that both principals and agents invest time and resources into maintaining (Scheberle, 2004). In other cases, there may be regional variations that are systematic based on inherent biases. Finally, our analysis does not consider whether EPA regional offices or state agencies are learning as part of this process. Consequently, future research should continue to investigate perceptions of best practices by EPA and state agencies, and their related impacts on environmental program processes and outcomes, especially as connected to regional variation, knowledge transfer, and policy learning. To that end, additional value-based metrics that are important to other stakeholders (e.g., environmental advocacy groups) may also be important in evaluating implementation practices (Ma, Becker, and Kilgore, 2009, 2012).

\section{Conclusions}

Environmental managers constantly explore innovative strategies to address environmental problems, and with this comes the development of new best practices. From a principal-agent perspective though, the problem to address are principal-agent problems, and innovative strategies must mitigate the core challenges related to information asymmetries and goal conflicts (Waterman and Meier, 1998). Within this framework, findings suggest three conclusions about best practices for environmental policy implementation within a federal system. First, although always focused on improving a problem, some best practices may address a problem internal to policy implementation processes, and not directly affecting environmental quality (Hall and Jennings, 2008). For instance, using data management tools may not improve environmental outcomes, but they do likely improve the policy implementation process. Ideally, this will eventually reduce transaction costs incurred in monitoring and reporting processes, and lead to more efficient processes (Waterman and Meier, 1998; Brown and Potoski, 2003). However, in the short-term, these practices only directly address issues of information sharing. As such, an important aspect of understanding what impacts best practices have on environmental management is identifying which problem these practices mitigate.

Second, principal-agent relationships are one of the key challenges of intergovernmental or inter-organizational policy implementation. Given the current reliance on third-party agencies for policy implementation, this is an inescapable reality. Consequently, it is important that policy implementation practices take into consideration management of these relationships, especially as many environmental agencies serve as both agents and principals. Within this framework, the best agencies are those that serve as both "good" agents and "good" principals. For instance, EPA considers the best state environmental programs to be those that effectively manage data, comply with obligations, identify violations, and apply enforcement tools. Third, for practitioners, these findings provide a framework for understanding why certain practices are better than others in policy implementation. As such, environmental managers can use this framework to begin to parse out what practices best mitigate principal-agent problems, or to identify where conflicts in their relationships with other organizations originate. In sum, principal-agent relationships are a fundamental part of implementing federal environmental policies in the U.S., and a set of best practices can help mitigate the inherent problems that emerge in such relationships. 
This is an author-produced, peer-reviewed version of this article. The final, definitive version of this document can be found online at Journal of Environmental Planning \& Management, published by Taylor \& Francis. Copyright restrictions may apply. https://doi.org/10.1080/09640568.2019.1670627

\section{References}

Agranoff, R. and M. McGuire. 2001. American Federalism and the Search for Models of Management. Public Administration Review 61(6); 671-681.

Bretschneider, S., F.J. Marc-Aurele, and J. Wu. 2005. "Best Practices" Research: A Methodological Guide for the Perplexed. Journal of Public Administration Research \& Theory 15(2): 307-323.

Brown, T.L. and M. Potoski. 2003. Transaction Costs and Institutional Explanations for Government Service Production Decisions. Journal of Public Administration Research \& Theory 13(4): 441-468.

Carpenter, D. and G.A. Krause. 2015. Transactional Authority and Bureaucratic Politics. Journal of Public Administration Research \& Theory 25(1): 5-25.

Centner, T.J. and N.S. Eberhart. 2016. The Use of Best Management Practices to Respond to Externalities from Developing Shale Gas Resources. Journal of Environmental Planning \& Management 59(4): 746-768.

Creswell, J.W. and C.N. Poth. 2018. Qualitative Inquiry and Research Design: Choosing among Five Approaches, $4^{\text {th }}$ ed. Thousand Oaks, CA: Sage.

Davis, R.S. and E.C. Stazyk. 2015. Developing and Testing a New Goal Taxonomy: Accounting for the Complexity of Ambiguity and Political Support. Journal of Public Administration Research \& Theory 25(3): 751-775.

Hall, J.L. and E.T. Jennings. 2008. Taking Chances: Evaluating Risk as a Guide to Better Use of Best Practices. Public Administration Review 68(4): 695-705.

Hedge, D.M., M.J. Scicchitano, and P. Metz. 1991. The Principal-Agent Model and Regulatory Federalism. Western Political Quarterly 44(4): 1055-1080.

Hindmoor, A. 1998. The Importance of Being Trusted: Transaction Costs and Policy Network Theory. Public Administration 76(1):25-43.

Howlett, M. 2004. Administrative Styles and Regulatory Reform: Institutional Arrangements and Their Effects on Administrative Behavior. International Public Management Journal 7(3): 317-333.

Howlett, M. 2005. What is a Policy Instrument? Policy Tools, Policy Mixes, and Policy-Implementation Styles. In Designing Government: From Instruments to Governance edited by P. Eliadis, M.M. Hill and M. Howlett (pgs. 31-50). Montreal: McGill-Queen's University Press.

Jennings, E.T. and J.L. Hall. 2012. Evidence-based Practice and the Use of Information in State Agency Decision Making. Journal of Public Administration Research \& Theory 22(2): 245-266.

Konisky, D.M. 2007. Regulatory Competition and Environmental Enforcement: Is There a Race to the Bottom? American Journal of Political Science 51(4): 853-872.

Koski, C. 2007. Regulatory Choices: Analyzing State Policy Design. Law \& Policy 29(4): 407-434.

Lane, J. 2006. Public Administration and Public Management: The Principal-Agent Perspective. New York: Routledge.

Lester, J.P. 1995. Federalism and State Environmental Policy. In Environmental Politics and Policy: Theories and Evidence, $2^{\text {nd }}$ ed. Durham, NC: Duke University Press.

Ma, Z., D.R. Becker, and M.A. Kilgore. 2009. Characterising the Landscape of State Environmental Review Policies and Procedures in the United States: A National Assessment. Journal of Environmental Planning \& Management 52(8): 1035-1051.

Ma, Z., D.R. Becker, and M.A. Kilgore. 2012. Barriers to and Opportunities for Effective Cumulative Impact Assessment within State-Level Environmental Review Frameworks in the United States. Journal of Environmental Planning \& Management 55(7): 961-978.

Matland, R.E. 1995. Synthesizing the Implementation Literature: The Ambiguity-Conflict Model of Policy Implementation. Journal of Public Administration Research \& Theory 5(2): 145-174.

May, P.J. and R.J. Burby. 1996. Coercive versus Cooperative Policies: Comparing Intergovernmental Mandate Performance. Journal of Policy Analysis \& Management 15(2): 171-201.

May, P.J. and R.S. Wood. 2003. At the Regulatory Front Lines: Inspectors' Enforcement Styles and Regulatory Compliance. Journal of Public Administration Research \& Theory 13(2): 117-139.

May, P.J. 2005. Regulation and Compliance Motivations: Examining Different Approaches. Public Administration Review 65(1): 31-44.

Mees, H. and P. Driessen. 2019. A Framework for Assessing the Accountability of Local Governance Arrangements for Adaptation to Climate Change. Journal of Environmental Planning \& Management [available online].

Miller, G.J. 2005. The Political Evolution of Prinicpal-Agent Models. Annaul Review of Poltiical Science 8: 203225.

Miller, G.J. and A.B. Whitford. 2002. Trust and Incentives in Principal-Agent Negotiations. Journal of Theoretical Politics 14(2): 231-267. 
This is an author-produced, peer-reviewed version of this article. The final, definitive version of this document can be found online at Journal of Environmental Planning \& Management, published by Taylor \& Francis. Copyright restrictions may apply. https://doi.org/10.1080/09640568.2019.1670627

Milward, H.B. and K.G. Provan. 2000. Governing the Hollow State. Journal of Public Administration Research \& Theory 10(2): 359-379.

Milward, H.B. and K.G. Provan. 2003. Managing the Hollow State: Collaboration and Contracting. Public Management Review 5(1): 1-18.

Myers, S.M., H.P. Smith, and L.L. Martin. 2006. Conducting Best Practices Research in Public Affairs. International Journal of Public Policy 1(4): 367-378.

Paul, M. and A. Milman. 2017. A Question of 'Fit': Local Perspectives on Top-down Flood Mitigation Policies in Vermont. Journal of Environmental Planning \& Management 60(12): 2217-2233.

Peters, B.G. 2014. Implementation Structures as Institutions. Public Policy \& Administration 29(2): 131-144.

Peterson, P.E. 1995. The Price of Federalism. New York: Brookings Institute.

Poth, S. and T.J. Selck. 2009. Principal Agent Theory and Artificial Information Asymmetry. Politics 29(2): 137144.

Posner, P. 2007. The Politics of Coercive Federalism in the Bush Era. Publius 37(3): 390-412.

Potoski, M. 1999. Managing Uncertainty through Bureaucratic Design: Administrative Procedures and State Air Pollution Control Agencies. Journal of Public Administration Research \& Theory 9(4): 623-640.

Potoski, M. 2001. Clean Air Federalism: Do States Race to the Bottom? Public Administration Review 61(3): 335342.

Ruffing, E. 2015. Agencies between Two Worlds: Information Asymmetry in Multilevel Policy- making. Journal of European Public Policy 22(8): 1109-1126.

Scheberle, D. 2004. Federalism and Environmental Policy: Trust and the Politics of Implementation, 2nd ed. Washington, DC: Georgetown University Press.

Scheberle, D. 2005. The Evolving Matrix of Environmental Federalism and Intergovernmental Relationships. Publius 35(1): 69-86.

Terman, J. and R. Feiock. 2015. Third-Party Federalism: Using Local Governments (and Their Contractors) to Implement National Policy. Publius 45(2): 322-349.

U.S. Environmental Protection Agency (EPA). 2005. Evaluation of the OECA/ECOS State Review Framework in Pilot States. [online] https://www.epa.gov/sites/production/files/2015-09/documents/eval-oeca-ecos-statereview-framework-pilot-projects.pdf [Retrieved July 1, 2018].

U.S. Environmental Protection Agency (EPA). 2010. State Review Framework (SRF) Definitions of the Status of Identified Recommendations. [online] https://www.epa.gov/sites/production/files/2013-08/documents/srfrd2-definitions.pdf [Retrieved July 1, 2018].

U.S. Environmental Protection Agency (EPA). 2018. State Review Framework for Compliance and Enforcement Performance. [online] https://www.epa.gov/compliance/state-review-framework-compliance-andenforcement-performance [Retrieved July 1, 2018].

Waterman, R.W. and K.J. Meier. 1998. Principal-Agent Models: An Expansion? Journal of Public Administration Research \& Theory 8(2): 173-202.

White, S.S. and M.R. Boswell. 2006. Planning for Water Quality: Implementation of the NPDES Phase II Stormwater Program in California and Kansas. Journal of Environmental Planning \& Management 49(1): 141-160.

Whitford, A.B. 2002. Decentralization and Political Control of the Bureaucracy. Journal of Theoretical Politics 14(2): 167-194.

Wholey, J.S. and H.P. Hatry. 1992. The Case of Performance Monitoring. Public Administration Review 52(6); 604610.

Wood, B.D. and R.W. Waterman. 1991. The Dynamics of Political Control of the Bureaucracy. American Political Science Review. 85(3): 801-828.

Wood, B.D. and R.W. Waterman. 1994. Bureaucratic Dynamics: The Role of a Bureaucracy in a Democracy. Boulder, CO: Westview.

Woods, N.D. 2006a. Interstate Competition and Environmental Regulation: A Test of the Race-to-the-Bottom Thesis. Social Science Quarterly 87(1): 174-189.

Woods, N.D. 2006b. Primacy Implementation of Environmental Policy in the U.S. States. Publius 36(2): 259-276.

Zahariadis, N. 2014. Ambiguity and Multiple Streams. In Theories of the Policy Process, ${ }^{\text {rd }}$ ed., edited by P.A. Sabatier and C.M. Weible (pgs. 25-58). Boulder, CO: Westview. 


\section{Figures}

Figure 1. Principal-Agent Relationships in Policy Implementation

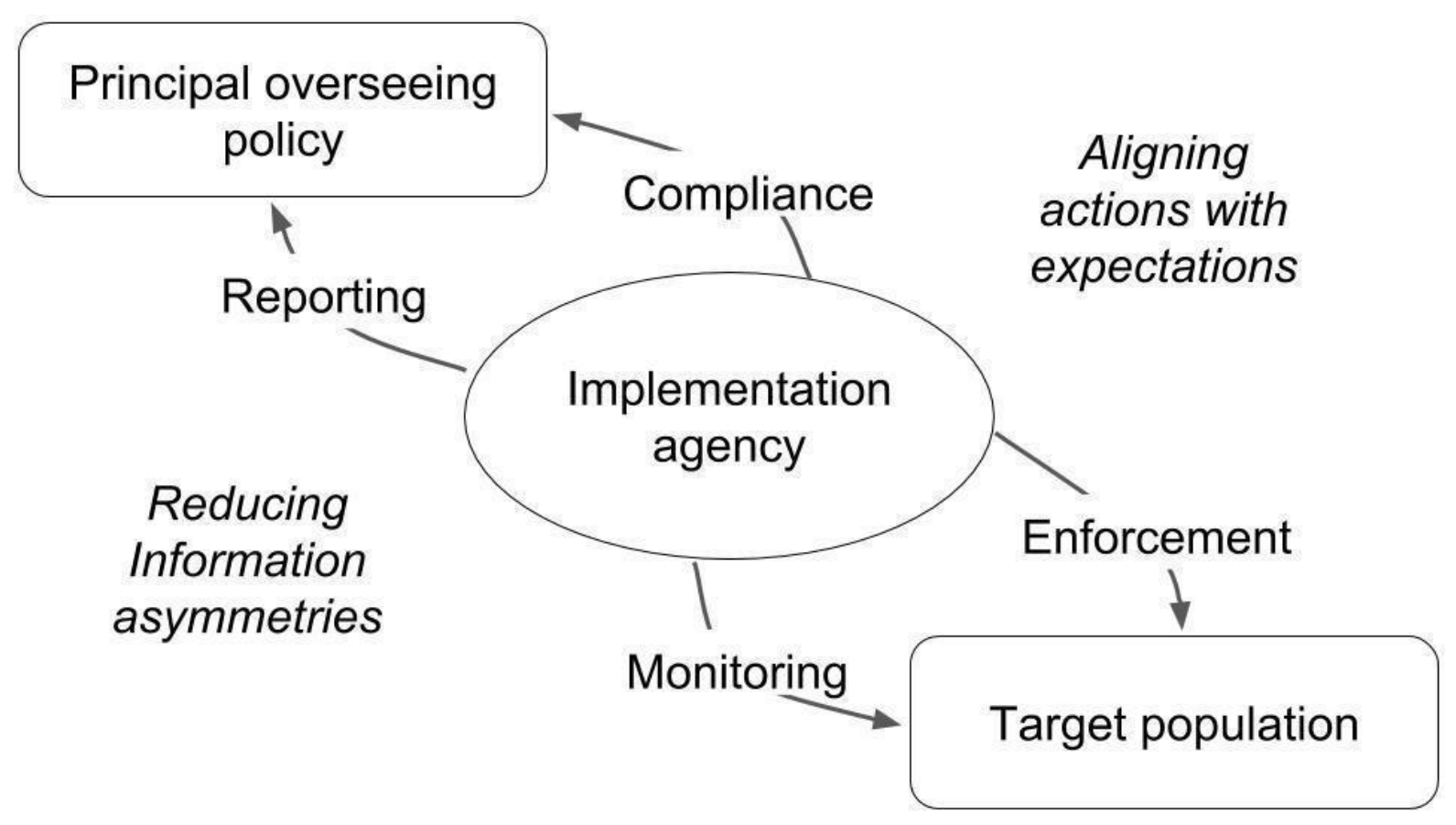

Figure 2. Best Practice Categories by Implementation Styles

\begin{tabular}{|l|l|ll|l|}
\hline \multicolumn{2}{|c|}{} & \multicolumn{2}{c|}{ Agency-level trust } \\
\cline { 3 - 4 } \multicolumn{2}{|c|}{ Low } & High \\
\hline \multirow{3}{*}{$\begin{array}{l}\text { Sectoral-level } \\
\text { trust }\end{array}$} & Low & $\bullet$ Reporting & $\bullet$ Compliance \\
\cline { 2 - 4 } & High & $\bullet$ Enforcement & $\bullet$ Eeporting & $\bullet$ Compliance \\
\hline
\end{tabular}

Figure 3. Best Practice Themes by Implementation Styles

\begin{tabular}{|c|c|c|c|}
\hline & \multicolumn{2}{|c|}{ Agency-level trust } \\
\hline & & Low & High \\
\hline \multirow[b]{2}{*}{$\begin{array}{l}\text { Sectoral-level } \\
\text { trust }\end{array}$} & Low & $\begin{array}{l}\text { - Be meticulous } \\
\text { - Be consistent } \\
\text { - Use a tiered approach }\end{array}$ & $\begin{array}{ll}\text { - } & \text { Focus on corrective action } \\
\text { - } & \text { Under-promise }\end{array}$ \\
\hline & High & $\begin{array}{l}\text { - Use data checkpoints } \\
\text { - Use checklists and templates }\end{array}$ & $\begin{array}{ll}\text { - } & \text { Be strategic } \\
\text { - } & \text { Link monitoring } \\
\text { - } & \text { Cross-train personnel }\end{array}$ \\
\hline
\end{tabular}


This is an author-produced, peer-reviewed version of this article. The final, definitive version of this document can be found online at Journal of Environmental Planning \& Management, published by Taylor \& Francis. Copyright restrictions may apply. https://doi.org/10.1080/09640568.2019.1670627

Table 1. Summary of Best Practices by Function

Use data checkpoints (4 best practices)

$$
\text { Reporting (24 best practices) }
$$

- Example from Massachusetts's CAA program: "MassDEP has designated a central point of contact within the state whose responsibility it is to review and quality control/quality assure the data. Although this process is time consuming and often requires manual data entry in AFS by this individual to resolve any issues, it has greatly improved data quality."

Be meticulous and record more than is required ( 20 best practices)

- Example from Arizona's RCRA program: “ADEQ maintains meticulous photo logs in their reports enabling the reader to easily assess the condition of the facility during the time of inspection."

Be strategic (2 best practices)

$$
\text { Monitoring (16 best practices) }
$$

- Example from Wyoming's CAA program: "Wyoming had negotiated and received approval for conducting compliance monitoring program pursuant to an alternative plan... The sources on a five-year inspection schedule are remotely located and have minimal observational value... State inspectors monitor compliance of these sites continuous every year by reviewing Title $\mathrm{V}$ compliance certifications and other compliance reports."

Link monitoring with enforcement \& reporting (3 best practices)

- Example from Arizona's CWA program: "Potential violations identified during an inspection are flagged... Complaints alleging violations are entered into a Complaint Report, and if inspected, are flagged in ADEQ's data system as compliant-response. When ADEQ inspectors enter their inspections reports into the AZURITE data system, an enforcement response may be warranted, "Cas-Rec" will be entered into the data system [and reviewed by inspector and manager]."

Use checklists and templates (11 best practices)

- Example from Alaska's CAA program: “ADEC has developed Onsite and Offsite FCE checklists to be used by all enforcement staff for consistency purposes... ADEC also has developed templates for all enforcement related correspondence such as FCE information requests (sent to facilities prior to initiating FCEs), FCE noncompliance corrections, and FCE in compliance letters."

\section{Compliance (17 best practices)}

Under-promise and over-deliver (14 best practices)

- Example from Maine's RCRA program: "HWCE has been able to consistently fulfill and go above and beyond its grant commitments despite grant monies that have dropped or remained level since 1997. As an additional challenge, the HWCE presently has to achieve its current commitments despite having 20 furlough/shutdown days between FY 2009-2011."

Cross-train personnel ( 3 best practices)

- Examples from Massachusetts's RCRA program: "Inspectors are trained to conduct multi-media inspections. Any inspection targeted may be inspected for all applicable media, which leads to a large number of sites visited annually."

$$
\text { Enforcement (11 best practices) }{ }^{1}
$$

Use a tiered approach (3 best practices)

- Example from New Hampshire RCRA program: "HWMB takes both informal and formal action (administratively and civilly be referral to the State Attorney General's Office (AG))... HWMB and State AG meet bimonthly to review all current cases and to make determinations."

Be consistent (4 best practices)

- Example from Oregon's RCRA program: “Codif[ying] the penalty assessment criteria inherent in EPA's RCRA penalty policy makes it clear to ODEQ and regulated entities what will be the basis for penalty calculations. This is a good practice because states have a firm basis for their penalties in their own regulations rather than in EPA policy."

Focus on corrective action ( 6 best practices)

- Example from Maine's CAA program: "MEDEP always seeks corrective action (injunctive relief or other complying actions), in its informal and, when necessary, its formal enforcement actions. The enforcement actions include clear and concise descriptions of the injunctive relief necessary and a timeframe for achieving compliance so that facilities with violations return to compliance."

\footnotetext{
${ }^{1}$ There is some overlap between best practices that use tiered approaches and that focus on corrective action.
} 